\title{
Capsule Commentary on Putman et al., Directive Counsel and Morally Controversial Medical Decision-Making: Findings from Two National Surveys of Primary Care Physicians
}

\author{
Nichole G. Zehnder, MD \\ Division of General Internal Medicine, Department of Medicine, University of Colorado School of Medicine, Aurora, CO, USA.
}

$\mathrm{J}$ Gen Intern Med 29(2):361

DOI: $10.1007 / \mathrm{s} 11606-013-2685-9$

(c) Society of General Internal Medicine 2013

$\mathrm{P}$ utman et al. ${ }^{1}$ utilized two independent cross-sectional surveys to investigate whether primary care providers (PCPs) are less likely to endorse directive counsel for "morally controversial" medical decisions compared to typical ones. The first survey asked abstractly about directive counseling, and found that physicians were less likely ( $35 \%$ vs. $65 \%$ ) to endorse directive counseling for morally controversial than typical decisions. The second survey included a clinical vignette of a patient requesting palliative sedation; in this case, $41 \%$ of providers endorsed directive counsel, while $51 \%$ endorsed avoiding influencing the patient's decision. Physicians were more likely to endorse directive counseling if the physician attended religious services, considered religion to be fairly or mostly important, or were less theologically pluralistic. It is interesting to note that the gap narrowed from the abstract question about morally controversial decision to a more concrete clinical vignette.

While limited by responder bias, ${ }^{2}$ the weak association between self-report and provider behavior and the crosssectional study design, this study suggests that physician beliefs affect their opinions about directive counsel for morally controversial decisions. It highlights the important tension between being directive and nondirective with respect to clinical decision-making. Physicians are not passive bystanders; they bring their own beliefs and biases to the conversation. Though this investigation examines directive counsel surrounding the specific scenario of palliative sedation, previous studies have found that physicians are more likely to reject directive counsel in similar morally controversial areas, such as sexual and reproductive health. ${ }^{3}$
For medical educators, these findings highlight how world views held by learners at all levels may impact the art of respectfully counseling patients regarding both typical and morally controversial medical decisions. If this hesitancy translates to providing less information, this could be important; shared decision-making is complex, and one of our primary duties is support and enhance patients' abilities to make autonomous decisions about their care. ${ }^{4}$ The line between directive counseling and nondirective counseling can be difficult to delineate. While it is a truism that we should not impose our own beliefs or value systems on patient decision-making, if we hesitate to provide adequate counseling we also fail as providers. Further research is needed.

Conflict of Interest: The author has no conflicts of interest with the material in this article.

Corresponding Author: Nichole G. Zehnder, MD; Division of General Internal Medicine, Department of Medicine, University of Colorado School of Medicine, Mail Stop F-782, 12401 E. 17th Avenue, Aurora, CO 80045, USA (e-mail: Nichole.zehnder@ucdenver.edu).

\section{REFERENCES}

1. Putman MS, Yoon JD, Rasinski KA, Curlin FA. Directive counsel and morally controversial medical decision-making: findings from two national surveys of primary care physicians. J Gen Intern Med. 2013; doi:10.1007/ s11606-013-2653-4.

2. Asch DA, Jedrziewski MK, Christakis NA. Response rates to mail surveys published in medical journals. J Clin Epidemiol. 1997; 50(10):1129-36.

3. Yoon JD, Rasinski KA, Curlin FA. Moral controversy, directive counsel, and the doctor's role: findings from a national survey of obstetriciangynecologists. Acad Med. 2010; 85(9):1475-81.

4. Guill TE and Brody H. Physician recommendations and patient autonomy: finding a balance between physician power and patient choice. Ann Intern Med. 1996; 125: 763-9.

Published online November 6, 2013 